This is the accepted manuscript of the article, which has been published in the

British Journal of Sociology. 2019, 70(4), 1159-1178.

https://doi.org/10.1111/1468-4446.12606

\title{
Group formation, styles, and grammars of commonality in local activism ${ }^{1}$
}

\author{
Eeva Luhtakalllio
}

University of Tampere

\begin{abstract}
This article argues that in order to analyze democracy as a pattern constantly processed in a given society, it is useful to look at activist groups' agenda setting and recruitment principles, group bonds and boundaries, and how these actions direct and influence ways of creating the common. Based on an ethnographic study on bicycle activism in Helsinki, Finland, it describes a local critical mass movement that was successful in promoting a bicycle friendly and sustainable city, yet dissolved due to lack of people involved, and the bicycle demonstrations stopped at a moment of high public interest. This empirical puzzle is addressed by combining three theoretical perspectives: Kathleen Blee's work on path dependencies in nascent activist groups; Nina Eliasoph and Paul Lichterman's work on group styles, and Laurent Thévenot's work on the grammars of commonality. These theoretical tools help understand the sense of what is deemed possible, desirable and feasible in activist groups, and the consequences thereof to social movement "success" and "failure". The article claims that everyday practices and interaction are crucial in understanding the "democratic effects" of social movements. It concludes that following specific processes of politicization and their conditionings in activist groups provide keys to understanding contextual differences in democracies without resorting to methodological nationalism or to exaggerated global isomorphism, and thus may contribute to figuring out how to succeed global action plans over wicked, pressing problems like global warming.
\end{abstract}

\section{Introduction}

\author{
May 9, 2017, Helsinki Critical Mass Facebook page: \\ -When is CM 2017? \\ -Unfortunately there are no Critical Bike Rides in planning for the time being. The main \\ reason is that voluntary organizers have not been found - in the planning meeting last fall, \\ no-one apart from the previous organizers showed up. \\ -What a pity! :( \\ Could you add this information also to the front page?
}

\footnotetext{
${ }^{1}$ I am grateful to Veikko Eranti and Lotta Junnilainen for their thoughtful comments and support in finalizing this article. Earlier versions of the text have greatly benefited from comments by Georg Boldt and Maija Jokela; Ricca Edmondson and Nina Eliasoph; the Hepo Seminar participants; Lotta Haikkola, Kaisa Kuurne, Anna Leppo and Mianna Meskus from the Ethnography Circle; as well as the two anonymous reviewers of the BJS. The research this article is based on was funded by the Academy of Finland and the Finnish Cultural Foundation.
} 
This article investigates a puzzle concerning an activist group organizing the critical mass demonstrations in Helsinki, from a revival of the rides in 2010 to the dissolving of the organizing group in 2016, and finally to the break of the over 30 years of local critical mass organization. During the years of this fieldwork, bicycling became increasingly popular, the city bicycle policies enhanced, expanded, and diversified, bicycle activists got several claims through and lots of media attention, and collective rides gathered big crowds. Bicycling became a matter of a heavy-duty power struggles in local politics. Yet, in the midst of this bustle, and a triomphant bandwagon to ride on, the critical mass movement in Helsinki slowly but surely withered away.

Kathleen Blee (2012) has argued that in order to understand how activist groups contribute to the formation of democratic practices they are widely acknowledged for (e.g. de Tocqueville 1961; Warren 2001; Fung 2003; della Porta 2009), we should study them longitudinally, and from the viewpoint of their inside interaction, more than has been common in the mainstream social movement studies. Both longitudinal analysis and group interaction have for long been topics of social movement analysis (for early calls see, respectively Klandermans 1992; Fine 1995), but combining the two has been less common. Blee $(2012,6-8)$ claims that in order to reach a level of analysis in which we could understand the different dimensions and multi-faceted effects of activist groups to democracy, it is necessary to pay attention to activist groups' development in time, as well as to both successful and unsuccessful groups.

In this study, I follow the path of a bicycle activism group in relation to the city of Helsinki sustainability and bicycling politics, as well as more generally in the context of Finnish political culture and the means of legitimization used therein. The aim is to understand, by paying attention to the group interaction and styles (Eliasoph \& 
Lichterman 2003), as well as to the prevalent grammars of action that shaped the group situations, features of the political culture this empirical puzzle emerged from, and the means of building common ground and solving controversies that made sense to the actors involved (Boltanski \& Thévenot 1991; Thévenot 2006; 2007; 2015; Luhtakallio 2012; Ylä-Anttila \& Luhtakallio 2016; Luhtakallio \& Tavory 2018).

When I set off to study grassroots climate politics in order to find out what kind of local permutations such a mega-scale global issue as the climate change triggers and sustains ${ }^{2}$, bicycle activism, and the Critical Mass movement in particular, seemed like the perfect pick. The Critical Mass movement's roots are in the 1960s-70s environmental movement and it has promoted the idea of sustainability long before climate became a dominant issue in environmental activism (Furness 2010; Vivanco 2013). Furthermore, promoting bicycling was, in the mid 2000s, quickly becoming a trend all over the Global North (see e.g. ECF 2017).

In Helsinki, the main organizers of the Critical Mass were the Helsinki Cyclists' Association, and the Friends of the Earth Helsinki (for historical overview see Luhtakallio et al. 2012). The Helsinki Cyclists (HeCy), founded in 1981, advances cycling conditions and represents its 1800 members (HeCy 2018). The Friends of the Earth (FoE) Finland has since 1996 advocated for "a more just, equal and ecologically sustainable world" (FoE 2018) as part of the Friends of the Earth International network. The FoE had been the principle initiator of the current form of Critical Mass in Helsinki, and has a central role in Finnish civil society climate politics. The alliance between the two associations prooved difficult: an underlying tension between the stakeholder

2 This study was originally part of a large research project on civil society and climate change (Alapuro 2010; see also Ylä-Anttila et al. 2018). 
interest and technical development based understanding of the movement's political agenda of the $\mathrm{HeCy}$, and the general interest and collective struggle based one of the FoE, set the group on a tricky path of avoiding internal political conflicts. In this sense, their story is quite proper to Finnish activist culture by and large, and its difficulties in dealing with conflict (see Luhtakallio 2012).

During the time of my fieldwork, the Critical Mass movement in Helsinki discussed, initially to my surprise, the movement's stance on environmentalism scarcely. Climate politics did not figure as a theme in public talks, or in post-demonstration events. Nevertheless, the critical mass formed the highly visible backbone to a rather successful movement promoting a more climate and bicycle-friendly city, and managed several political gains in terms of sustainable transportation and infrastructure. In order to analyze this puzzle, and furthermore to increase understanding on the importance of the everyday practices and interaction to the "democratic effects" of social movements, I examine the group interactions on agenda setting and recruitment (Blee 2012), and the group style (Eliasoph \& Lichterman 2003) adopted by the activists in their efforts to build common ground (Thévenot 2007) in the group settings.

\section{Group formation, styles, and the grammars of commonality in patterning democracy}

Kathleen Blee (2012) claims that group dynamics direct activist groups from the very beginning and create path dependencies that are hard to change later. From the initial choice of agenda to member recruitment principles, to the extent of loss of seemingly all democratic potential, the falling apart of the group, or, on the other side of the coin, 
fruitful actions that may have very little to do with the original plan of action, Blee shows how group dynamics created these paths and sustained them (ibid. e.g. 33-39).

Nina Eliasoph and Paul Lichterman (2003) have approached similar questions concerning how groups come to be what they are: how a group "culture", embedded in the interaction between group members, creates and modifies shared understanding of group bonds, boundaries with the outside world, and speech and action norms within group settings, and how these features are constitutive in understanding what activist groups do and why (ibid. 737-738, 785-786). How do group members relate to each other and how do they collectively define the relations they have with each other? How do they decide on the ways of dealing with outsiders, or on who to recruite and why? What kinds of topics are appropriate to discuss in the group and how can they be talked about, and which action repertoires the group chooses to use? These are questions that arise from combining the group styles approach with Blee's theory on activist group paths and turning points.

Studying the group styles of Finnish and French local activists (Luhtakallio 2012), I found that "success" was an extremely subjective matter to the activists themselves. They acknowledged external evaluation to a certain extent, but the groups' own understanding of the successfulness of their actions did not depend on, or always conform to it. Instead, a particular group culture and style that directed the bonds, boundaries, and speech and action norms of the group, together with the dynamics between this style and the surrounding political culture, were prevalent to how the group evaluated success. Also, the question of politicization - how easy or complicated it turned out to be for the group to come up with a conflict that had general interest and could be successfully publicized (see Hamidi 2006, Carrel 2015) - depended greatly on the group interaction 
context, and its relation to the wider cultural preferences of activist interventions. In the Finnish context, expertise and a non-conflictual, even technical style have been repeatedly noted as the widely acknowledged characteristics of "good activist conduct" (see eg. Berglund \& Harper 2001; Luhtakallio 2012), but this style has also proven potentially prone to jeopardize politicization (see Luhtakallio 2012, 60-62, 170-173).

The democratic effects of social movements have been acknowledged from multiple viewpoints (e.g. Fung \& Wright 2001; Warren 2001; Valocchi 2009) and social movement success and failure been addressed in a large body of literature (e.g. McCarthy \& Zald 1977; Klandermans 1984; Edwards \& Gillham 2013; Snow \& Benford 1988; Koopmans \& Statham 2010; Snow et al. 2014). Yet, social movement actions continue to be intuitively difficult to pinpoint: the effects are often indirect, and may occur in waves, intermingled with other, simultaneous processes.

In order to capture these processes, we need to address successes and failures at different levels of politicization, the driving force of social movement mobilization, and a key feature in creating "the common". Laurent Thévenot has suggested that three grammars of "commonality in the plural" format the processes of working the shared that people engage in: the grammar of public justifications, based on competing, yet recognized and legitimate conceptions of the common good; the grammar of individual interests (for terminology see Eranti 2018) based on stakeholder interests, negotiations and deals; and the grammar of familiarity based on intimate attachments to shared "common-places", recognized, yet often non-verbalized loci of comfort and ease (Thévenot 2007; 2014; 2015). These three modes of communicating and composing the shared and acknowledging difference have proven useful tools to analyze (and compare) different cultural contexts, and the instances in which "democracy" as a form of governance is 
forgerd into being (on urban planning and participation Blok et al. 2018; Eranti 2017; on local activism Luhtakallio 2012; on populist politics Ylä-Anttila 2017). Introducing this theoretical framework in the case of the bicyclists is part of the adbuctive approach to analyzing this empirical puzzle I have deployed (Tavory \& Timmermans 2014), yet it also evolves from challenges I identified working with the group styles approach to better spell out their processes of emergence and the relation thereof to the wider context of political culture.

Examining democracy as a setting for multiple processes of politicization enables to see it as a pattern of the "common ground", instead of a stable institution or a structure. From the viewpoint of democracy as a pattern of commonality, following specific processes of politicization and their conditionings and reflections by activists interacting and acting in groups is a key to making sense of what and why seems possible, desirable, and feasible to change in a given context.

In the following, I analyze the Helsinki bicycle activists' agenda setting process and their effots to forge the common therein. I explore the contradictions between the external outcomes and the development of the internal dynamics of the activist group: external "success" did not translate into internal coherence, and vice versa, the internal difficulties of the group formation did not stop external "success", until a certain breaking point. Understanding these contradictions enables building a link to the original puzzle of what happened to climate campaigning and critical mass activism in Helsinki and why, and how does it matter.

Helsinki Critical Bike Ride Group: Bonds, boundaries, and politics 
Helsinki is part of the biggest metropolitan area of Finland with a population of about 500000 (in the city). There are $1200 \mathrm{~km}$ of bike lanes in the city (Helsinki 2017), and cycling covers about $6 \%$ of daily travels (Helsinki City Planning 2014). In contrast with its Nordic neighbors Copenhagen - a world-famous cycling city - and Stockholm, in Helsinki, cycling has not been a primary policy concern before the past decade, when modest progress has been made in terms of planning up to date bicycle infrastructure (Helsinki City Bike Plan, 2014).

I conducted fieldwork among the group that organized the critical mass in Helsinki between fall 2010 and spring 2015, after which I continued to follow the group's activities mainly online. During the first years of fieldwork, I took part in the monthly critical bike rides and attended planning meetings, after ride gatherings, chat, Facebook and email discussions, picnics, parties, and other events organized by the Critical Mass movement. ${ }^{3}$

After initial steps to enter the field, my fieldwork was guided by a methodological approach situated between theory-driven ethnography (Lichterman 2002) and, at a later phase, abductive analysis (Tavory \& Timmermans 2014). With the ambition of understanding both the problematic of climate politics in local activism and the consequences of activist practices in the "patterning" of democracy in a given context, I began to focus on certain keywords and categories in the group interaction, notably mentions of politics and the activists' definitions thereof that were triggers of tension in the group (see Lichterman 2002, 139). Furthermore, defining politics was something the

3 I rode with the Critical Bike Ride 17 times (each ride took from 2 to 5 hours, depending on the length of the ride as well as the after-ride events), and attended about 40 other related events. I followed both the email and social media discussions of the group. The following analysis is based on fieldnotes I took in the events and right after them, on field interviews I conducted, and on online and printed material. 
activists themselves reflected on, and following this theme was, therefore, part of my effort to incorporate "members' meanings" into my analytical interpretations (Emerson, Fretz \& Shaw 2011, 129-130).

Drawing from my previous work on the adverbial use of concepts in comparative research by taking the actors' definitions of concepts such as democracy or citizenship as starting points of analysis (Luhtakallio 2012, 4-7), I focused on the activists' understandings of politics and activism as well as on their reflections on what was "the problem" in building the common ground in the group. Finally, Iddo Tavory's and Stefan Timmermans' work on abductive analysis (2014) became gradually important in the process of working analytically with the material from this field. The basic idea of abduction as a methodological approach is an iterative process from observer's surprise to de-femiliarization and to revisiting observations so that each surprise motivates speculative theorizing, as well as further focuses - or re-focuses - "what this is a case of" (Tavory \& Timmermans 2014, 52-61; Tavory 2016, 165).

When I began the fieldwork in fall 2010, the Helsinki critical mass - the "Critical Bike Ride" (CBR), as it was locally known ${ }^{4}$ - was experiencing an organizational crisis. The event had been coordinated by the Friends of the Earth Helsinki (FoE) for several years, and the key group of people involved had decreased to a couple of activists who had difficulties in keeping up zeal to organize the event. The rides were small, around 30-40 people maximum participated, and the route was always the same. There were no particular efforts to spread the word: it was, for instance, nearly impossible to find any up to date information on the rides in the Internet. The current organizers' resources to

\footnotetext{
${ }^{4}$ The name Critical Bike Ride is due to the early cyclist demonstrations organizers' wish to differentiate the event as a bicycle ride, as the critical mass was, at first, a predominantly pedestrian event in Helsinki (Luhtakallio et al. 2012, 181-2).
} 
develop the rides were scarce: the event rested mainly on the shoulders of two FoE activists, Milla ${ }^{5}$ (female, in her late 20s) and Magi (male, in his early 20s). The moments before the ride began when people gathered on the square and waited around, and after the ride when people, again, stayed for a bit talking to each other were telling: both occasions were uneventful, marked by a collective confusion over the lacking structure. There were no public talks or declarations, hardly a "welcome all, let's ride", quickly uttered by either of the two organizers. Thus, the event took place relying on people who knew what was going on, but it seemed somewhat halfhearted and disorganized. Shortly after I had joined the monthly rides, the organizers, well aware of the shortcomings of the organization, took the initiative to invite people to join a discussion about the organization after the ride.

This is where I begin my description of the emergent group culture (cf. Blee 2012, 17), as it turned out that this was the moment the new organizing group for the CBR took its first steps.

\section{The trouble with politics}

The second time I took part in the critical bike ride, in September 2010, Milla, the aforementioned FoE activist, announced in the beginning of the ride, speaking into a megaphone, that a meeting concerning the organization of the rides was to take place in a near-by restaurant right after the ride. The first meeting attracted about ten people, who gathered together after the ride, led by Magi, the other FoE activist. In the first meeting, the diversity of the particpants' backgrounds in terms of bicycling as well as

\footnotetext{
${ }^{5}$ All names are pseudonyms.
} 
ideas about the CBR soon became evident. The following extract from my fieldnotes describes the first meeting's atmosphere and the challenging starting point of what was to become the new organizing group for the Critical Bike Ride.

The ambience is a bit awkward and people mope each other; most have seemingly not met before. Heikki (male, in his 40s) starts by telling he's a bicycle activist and owns 21 bicycles. He asks whether once every two months would be a more reasonable cycle for the event, and whether it should be more directed towards families. Matti (male, in his late 30s) presents himself as the father of 7 and 4 year old sons and says he is 'more of a political cyclist than a gym enthusiast'. He goes on to talk about the 'dreadful' situation of major bike lanes in Helsinki. Yet, he stresses that the CBR isn't and should in no way be against car driving. Pertti (male, in his 50s) says he's been on his first CBRs in the 70s and 80s. Heikki, Matti and Pertti dominate the discussion. Magi tries to get the introduction round back on track, but he is very gentle in interrupting the talkative men. Merja (female, in her early 30s) says that the information on the CBR is currently really lousy and suggests a Facebook page, saying that in her view, 'The CBR is a political event and not a family picnic or a kids' event'. Her tone is rather confrontational and she directly contradicts Heikki's and also Pertti's ideas. The ambience gets tense, the two men lean back looking discontented. Magi adds that 'as a totally private person' he thinks 'we should struggle against cars as much as possible and even make provocation'. Contradicting ideas float about, without anyone actually responding. Pertti and Matti launch a lengthy discussion about the height of the paver brinks and other details affecting cycling. People are getting to look tired. No-one has kept minutes, and the meeting disperses with no clear ending, nor announcement of 
what will happen next. Some people greet each other 'see you next month', at the next CBR.

The tensions and disagreements that nobody could figure out how to tackle, weighed on the atmosphere. What began as something that already took a lot of courage to join - a meeting between people who were mostly total or almost strangers to each other and had decided to participate on the spot - became increasingly confusing and hard to handle. Nobody was in charge of the procedural side of the meeting; the disagreements occurred without prior warning and were left unsolved. Notably, in the midst of the introductory round that took more than an hour to finish, a few participants laid out the grounds for things that became constitutive of the group's discussions, and created a path dependency that affected the group's future actions: disagreement regarding the relation of the CBR to "politics", and the agenda it should promote, as well as the recruitment base the participants saw possible and desirable for the CBR in the future (see Blee 2012, 35-6, 53, 82-3). The most blatant points of disagreement among the meeting participants - whether the CBR was or should be a political event or not, and in what way, and whether the organizers were and/or should be "activists" - came up bluntly and were more or less not reacted upon. These features display, paraphrasing Blee (ibid. 85), the first efforts of the group to exercise political imagination - to define the scope of the activities, and thus define the particular limits of the possible for their actions (see Baiocchi et al. 2015). Also at display were the first occurrences of forging the common of this collectivity-to-be, illustrated in conflicting attempts to build common arguments based on efficiency and good communication, and on raising collective struggle ${ }^{6}$.

\footnotetext{
${ }^{6}$ In terms of the theory on justifications, this conflict represents a controversy within, respectively, the industrial world (testing what is efficient), and the civic world (testing what is fair and equal - opposing cars or not, for instance) (Boltanski \& Thévenot 1991; Ylä-Anttila \& Luhtakallio 2016).
} 
In the next after-ride meeting, a month later, more (of the same) tensions arose, but the organizing group also did begin to take shape.

Magi, Pertti, Matti, Merja, and a few others that I don't know are present. Another introduction round is ongoing. I say I'm doing research on local climate activism, and notice the mistake immediately as Matti hurries to say very firmly "Now, I'm under no circumstances a climate activist, this is NOT climate activism!”. The FoE activists, Magi and Milla, look at each other with slightly raised eyebrows and fidget on their chairs. However, nobody says anything. Matti fires: 'Getting rid of FoE and getting $\mathrm{HeCy}$ in the lead instead is good for purely marketing reasons'. Magi looks troubled, with a wrinkle above his nose. Nobody says anything in response.

Matti continues to press: 'Everybody doesn't necessarily want to take part in a demonstration - some selling, come on!' Magi notes, a bit dryly, 'Well it is after all a demonstration'. Also Arho wants the CBR to be 'less demonstrationlike'. Merja says 'But there should still be a message of some kind, I mean, the starting point is that we want something, right?' The meeting ends, again, in a confused atmosphere and concludes nothing organizationally. Magi says 'Well we don't have to decide anything now, we can have another meeting'.

In the second meeting, the confusion between the different understandings of the common ground grew deeper. My clumsy mistake in the beginning of the above excerpt - which at this early point of fieldwork was not an intentional stimulus by tossing in a definition to see how the members would react (see Lichterman 2002) but plain clumsy ${ }^{7}$

\footnotetext{
${ }^{7}$ For instance Lichterman (2002, 118-9,) points out how ethnographers' faux pas can turn useful, even central clues in analyzing field events (see also Musante \& DeWalt 2010, 61-64).
} 
- showed the inner tension of the group; the FoE activists were first and foremost climate activists, and identified as activists, whereas the others, including the one who fiercely corrected me, showed varying degrees of prejudices towards activism altogether. This discrepancy was not prevalent exclusively between activist identifications. As the turns in the discussion that followed show, it occurred also, and more importantly, between engagements in the logic of civic justifications - "it is a demonstration"; "we want something" - and engagements following the logic of strategic, interest-based planned action - "some selling, come on!". There were two clashing, incompatible grammars of composing commonality in this situation - one that aimed at a shared understanding of a common good, and another that aimed at fulfillment of stakeholder interests by mobilizing a quasi-opportunistic vocabulary concerning action repertoires (in which demonstrating as such had no legitimacy, but could be tolerated as a form of strategic marketing). This clash of grammars, or in other words the group's difficulty in creating a necessary common ground in order to work together, had long-standing consequences.

The participants of these meeting were, naturally, very much aware of the difficulties that the divided understandings of action repertoires and agenda of the CBR altogether caused. In discussions with only "one side" of the controversy present, the $\mathrm{HeCy}$ members debated their own definitions of politics, and questioned the reluctancy from their part to "go political" with the event. Once, they challenged me, as "a specialist", to help them reflect what politics and activism actually were. This resulted in a long discussion on Finnish political culture, with my interlocutors finally concluding that the weight of history - the civil war, the finlandisation era, and the fear of deportations to Siberia by the Soviet Union - were still strong markers today. In addition, the image of activism some of the HeCy members had reflects the foolish, if not outright dangerous 
representation of activists that became prevalent in the Finnish public sphere during the politically turbulent years of the 1960s and 1970s, and still has leverage today (see Berglund \& Harper 2001, 6; also Lundbom 2016). Similarly, the FoE activists, when among themselves, had heated discussions on whether it made any sense to continue including CBR in their climate action set, as they saw clearly that they risked being steamrolled by the cyclists who had no ideological cause, or, had a right-wing one, as some of them suspected.

\section{Working the group bonds}

In 2011, the organizing group initiated a new form of side-events to the CBR: "The Cycling Night", a debate and lecture event, with different invited specialists and a changing theme of discussion. This idea was born as a kind of compromise to the controversy concerning the means of contention the CBR should use. The event had a political content, but the form of a seminar, with invited speakers from the Helsinki City administration and the university. Thus, it was "political" without "looking like a demonstration".

The venue chosen for the events was the Student House in the center of Helsinki, where the FoE occupied a space together with several other environmental and Leftist student associations. At the first Cycling Night, the organizers wanted to make the event a "relaxed" evening spent together, and this goal was further emphasized when the official programme ended up being somewhat thin due to a cancellation of one of the speakers. It turned out to be difficult to make the evening a relaxed one. The venue itself was homely with decoration made up from fleemarket furniture and old rugs, walls plastered with old campaign posters, and the FoE folks tiptoeing in their woolen socks, but this 
kind of homeliness was not necessarily prone to make the HeCy people feel at home, or even welcome. An uneasy incident took place right in the beginning: Mikko, a HeCy member, arrived to the event with a McDonald's take-away bag, sat down and began to take out his hamburger. The FoE activists, busy putting tea at offer, startled at the rustle of the paper bag and looked shocked. Magi then informed Mikko that the venue was “actually a vegan space, a meat-free space”. Mikko looked astonished, a long and frozen silence followed, after which Magi told Mikko to eat anyway, but to be aware of the house rules next time.

This incident, as short and passing as it was, manifests the arduousness of building common ground and trust in the group. The familiarity that FoE had established in its long-time venue was violated right in the beginning by the $\mathrm{HeCy}$ member who brought in the wrong kind of food by accident, and in turn, had his personal space infringed when his private snack moment was interfered. Instead of creating commonality through familiar attachments and by way of spending leisure time together, the event contributed more to the opposite. The Cycling Night never took place again, and it turned out to be equally difficult to establish other side events along the years, perhaps for many reasons each time, but the partial awkwardness of the events was never overcome completely.

By spring 2011, it was, nevertheless, finally settled that FoE and HeCy would organize the CBR together. The organizing group consisted loosely of the people present in the initial meetings, but also a handful of others, from both $\mathrm{FoE}$ and $\mathrm{HeCy}$, a bit fewer from the former, and a few people from outside these two associations. ${ }^{8}$ As the group mainly met once a month (although online contact was more frequent), it took a good while for

\footnotetext{
${ }^{8}$ The group composition and size varied between five and over a dozen so that more people attended the organizing group during the late spring, summer, and early fall months, the same way as with the rides.
} 
people to establish more familiar relations with each other, even though some of the key activists knew each other from other contexts. However, the relations between the environmentally oriented members of the group, and the more straightforwardly bicycleoriented members remained relatively distant, and even somewhat tense. The bonds specific to this group - shared knowledge on what bound them together and what kind of relations the group members had with each other (Eliasoph \& Lichterman 2003, 785786) - were not easily, if at all, established. The group couldn't conclude on a collective understanding of who "we" were, nor find strong or lasting objects or loci of shared attachments, and this had consequences to what it could do as a group, and, eventually, what it could have on its agenda.

The organization of the rides, however, gradually got easier and more energetic, and even managed to include small, usually on-the-spot improvised after-ride events. When a picnic was announced at the end of a ride, most people had nothing to eat or drink, and either didn't stay or improvised a quick visit to a near-by grocery store. Nevertheless, extending the rides to picnics and such, the group slowly learned to work together without having to deal with too fundamental conflicts. Instead, they joked about them, like when Magi suggested that in order to make CBR pins, the others could join a working party FoE was having to craft campaign material, and Arho responded "I can come there and be the supervisor who drinks beer". Magi, encouraged, asked if people would like to plan doing something "unofficial" together, which got Merja asking "Do you mean something civil disobedient by that, like cementing cobblestones?”.

Discussions taking on flirtatious tones when touching issues such as civil disobedience, resulted from the group members' awareness of their differing views regarding action repertoires. Addressing differences with humor made the group setting more pleasant, 
but also led, or contributed to, the quasi-dying out of the discussion over the agenda of the CBR. In order to maintain the joint plan to organize the rides and have "relaxed events", the group more or less abandoned efforts to compose solutions over conflicts.

These developments rendered the group organizationally quite functional - they were able to follow the plan, distribute tasks effectively and organize the rides effectively - but the agenda building diminished and nearly halted altogether. The group bonds were gradually established by keeping conflict at bay, and thus strengthening the predominance of the grammar of individual interests in the group culture; a tendency that has consequences to capacities to build processes of politicization (Luhtakallio 2012, 87-90). It was, however, not the only tendency that affected the political stances of the group: in the following, I turn to the issue of recruitment and defining of group boundaries.

\section{Drawing boundaries: who should join the ride?}

According to Blee (2012), one of the crucial things to look at in predicting the future of an activist group is what kind of recruitment principles the group adopts. Will this be an open or restricted group, and what kind of people do the group members collectively imagine as preferred future members? In terms of group styles, these processes are part of defining the group boundaries (Eliasoph \& Lichterman 2003, 785). In this section, I analyze the processes in which the recruitment principles of the CBR were discussed and defined, and how they affected the group's politicization initiatives.

Recruitment was a topic of the very first meeting of the organizing group, and it remained a recurrent theme throughout. What kind of people the event should attract 
was one of the questions the group had hard time reaching a consensus on due to the clashing of grammars different participants of the group originally deployed. Similarly to the controversy over the demonstration form and image of the rides, the organizers were in a quite stereotype-bound disagreement about what kind of people they wished to be rid of; for instance "army-coated, long-haired hippies", and the opposite, "the spandexwearing", professional bicyclist looking folks, both of whom allegedly cast out "normal people". Efforts to define "normal people" remained scarce, yet there was an assumption that everybody shared an idea of who and what kind they were. Once on a ride Timo, a HeCy member, pointed out to a man in a white shirt and tie and said: "See the guy who looks like a business man, there should be more of those, there should be people like that". The businessman look was, for Timo, a characteristic of "normal" - but for many, this was not the definition in mind. Heikki (also from $\mathrm{HeCy}$ ), for instance, often talked about the problem that the week day scheduling of the rides posed to recruiting people: "If the CBR was organized on Saturdays, it would be possible to get families along and organize also other activities, and we would get to expand the CBR wider than the HC (hard core) activism." Families with children, in Heikki's - and many others' - thinking were the kind of normal people the bicycle demonstration needed to attract. From the FoE side, initiative to have a loudspeeker bicycle riding with the CBR was justified with presumptions that music would attract "normal" people, in this case referring to hipsterish young students. It is noteworthy that whatever the characteristics of the desired recruitment base, they were neither environmental nor bicycle activists, thus the group collectively arrived at wanting to recruit in particular from outside its "own" recruitment basis.

The consensus the organizing group reached about recruitment was, eventually, that "everybody" should be able to join the rides. "Everybory" is not a collective, but an array 
of individuals - and thus, as with the bonds, the group boundaries were anchored in the grammar of interests and stakeholders: "Everybody" should join, the group should embrace a marketplace of ideas, and advance "all" stakeholder opinions present. Building the common ground both by way of a collectivity deliberating about a common good, or by becoming a close, intimate community were suppressed. While the interest-based way of building common ground is indeed possible, and widely spread in social life, it made decision-making about concrete recruitment of people to join - what from the outside looked like a social movement collectivity - quite difficult. As the definitions of the desired recruitment base were vague, almost euphemistic, it was hard to come up with ideas of how to target recruiment campaigns, and what to focus on in them.

\section{Politicization, success, and dissolution}

During its years of mobilization, the Critical Bike Ride organization group succeeded at several occasions in politicizing both bicycling in general, the city bicycle infrastructure and conditions for bicycling specific to Helsinki. One of their biggest moments of publicity and political visibility included the first ever bike ride that took over a highway near the center of Helsinki in September 2011. The attendance to this CBR was high, and included for instance the much-missed families with small children. The highlight of the ride was when the head of the cortege entered the highway connection.

When the first cyclists reach the highway, we hear cheering, whistling, and shouts of joy. I ride next to Merja, she says she still can't really believe we're actually going there. It is an exhilarating moment. Taking to the silent, empty three-lane highway makes people burst into spontaneous cries of joy, they ride raisings fists, someone jumps off his bike and lifts it above his head. "This is really awesome, I 
didn't think it would feel this different", says Merja. After the ride, there is a spontaneous gathering at a bar chosen on the fly. The ride has gathered about 260 cyclists (this is close to record for Helsinki bike rides), but at the bar we fit well at two tables. There are toasts and cheering, but also moments when nobody knows what to say or do next. Most drink one beer and leave. A guy I’ve never seen before calls out, leaving, addressing no-one in particular: "Thank you for today, this was really empowering."

The Western highway Critical Bike Ride evoked strong collective emotions on the spot. This shared experience, a true common-place in the sense that Thévenot (2015) describes - an emotional, non-verbal, sometimes intimate locus creating a collective memory that can be brought back by way of mutually recognizing a trace of reminiscence - nevertheless remained an isolated event, something that years later the participants could recognize as significant and shared, but that was not continued in the group as deepening familiarity, nor translated into a level of civic collectivity (cf. Ylä-Anttila 2017). It was empowering, but if there ever was a purpose to boost the movement as a political collectivity, this was not the effect it had.

Yet, the highway ride was notified widely in the media, both television, radio, and local and national press, and its main claim - that the incoming highways should be transformed into city boulevards with low speed limits and bike lanes - was well spread in the public debate. A motion suggesting the creation of city boulevards was issued at the Helsinki City Council just weeks after (by a Green Party councilor). ${ }^{9}$ So, not only did the bike ride manage to occupy public space both in concrete and in debate, the

\footnotetext{
${ }^{9}$ The city boulevard issue moved forward in years to come and the priciple was gradually accepted as part of the general zoning plan in 2016 (Helsinki 2016).
} 
politicization process thus set in motion moved forward and involved political decisiomaking.

Following this successful politicization, there were other similar victories that the Critical Bike Ride group could at least in part claim the ownership for. In 2012, the first cycling fast lane was opened in the Helsinki city center. In the transportation plans accepted in the following years, cycling got gradually more attention and a bigger budget. The cycling fast lane plan developed to cover the whole city by 2020. In 2016, the City Council accepted a plan to transform one of the main axes of the eastern city center into a public transport and cycling only street (Hämeentie 2016).

Each of the above points of "success" led, in the CBR group, to an attempt to celebrate the successfulness of the mobilization and to plan how to use the success to further the cause. These attempts failed, at least partially, time after time. Attempts to organize "festive" rides and parties worked out poorly. Further planning and agenda setting discussions either got stuck the way this paper has shown, or were moved to other circles, mainly ones that centered around the Green Party local politicians who were or had been active in the bicycle movement.

In 2014-5, the organization of the rides fell back in serious trouble, and the group, growing smaller and wearier, was desperately seeking new members. The discussions to solve the problems turned around the now familiar questions of whether the events should be more "fun" or more political, but as previously, the group could not arrive at a decision, and thus the definition of the activities remained vague. Consequently, they went in neither direction, and never got back to the questions of defining their political mission, or solving the conflicts concerning attitudes towards car driving, or climate 
politics. As Blee (2012) has noted, this is not unusual - activist groups may "get stuck" with directions set early on, even if this turns out to be detrimental to the mobilization or even the existence of the group. I have suggested that this may have resulted from the group withdrawing from building common ground as a deliberating, legitimacy-testing collectivity, and failing to establish a common ground based on familiarity, comfort, and ease. Instead, the group forged common ground as a community of interests in which “all” opinions and stakes were to co-exist. In the concluding section, I will reflect on these findings in relation to what previous research has suggested concerning the particularities of the Finnish political culture, as well as in relation to the theoretical discussion on democracy as a pattern that I began solving this puzzle with.

\section{Conclusion}

This article has argued that in order to analyze democracy as a pattern constantly processed in any given society, it is useful to look at activist groups' agenda setting and recruitment principles, group bonds and boundaries, and the ways these actions direct the group's creation of the common. These theoretical tools create a three-dimensional lens to the path dependencies of success and failure stemming from the group context; to the group styles directing the actors' meaning-making and understanding of the possible and the desirable, ie. their civic imagination (Baiocchi et al. 2015); and, finally, to the processes of creating common ground that bend towards either a public legitimacy and common good driven, an individual and stakeholder interest bound, or a familiar, close attachment and intimacy based grammar of commonality.

The Helsinki Critical Bike Ride group rode the global bandwagons of climate activism and bicycling for several years, and managed to introduce a regularly demonstrating mass 
bicycling movement that gained sigificant visibility. Furthermore, the group was involved in several successful politicization processes and managed to put significant pressure on decision makers. Yet, there was recurrent trouble of finding enough people to organize the events, and the group never really succeeded in creating the kind of atmosphere they hoped for. Even the emotionality of the highway rides did not contribute to strengthening group bonds, and the common-places thus created, or the gains in political processes, could not be mobilized. Finally, despite the success, the group was dissolved and the most visible display of bicycle activism in Helsinki stopped with practically no sign or sound. The quote in the beginning of this paper illustrates the blankness that characterized the end: there was no row, no final statement, and no attempt to manage the public image of the event. From the outside, the fading away of the organizing group is a mystery, looking at the increasing buzz and hype around cycling in Helsinki and globally, as well as the mainstreaming of global warming. From the inside it makes sense: the troubles and conflicts that were not solved in the beginning when the group began to form, followed the group all along, and finally boiled down to dissolving it.

In previous analyses of contemporary Finnish social movements, the prevalence of expertise and constructive, "efficiency-led", even consensual participation over contention and confrontational styles has been stressed (e.g. Siisiäinen 1992; Alapuro 2005; Berglund \& Harper 2001; Luhtakallio 2012). Risto Alapuro’s (2005) influential explanation grounds on the definition of representation in the Finnish context: in a nutshell, that the mediation of citizen-state relations by voluntary associations, and a dominating idea of the society as a transparent, thoroughly represented entity with no threatening, obscure forces looming behind. This considered, analyses of the features of the Finnish political culture from the perspective of grammars of commonality have recurrently found that in public justifications, there is a prevalence of the industrial 
"world" - political claims based on efficiency, expertise, scientific knowledge - in the Finnish public debate (Luhtakallio 2012; Gladarev \& Lonkila 2013; Perälä et al. 2013; Ylä-Anttila \& Luhtakallio 2016). In other words, expert argumentation rather than contentious claims for rights, for instance, is found widely legitimate in Finnish civic imagination (see Berglund \& Harper 2001; Berglund 2006). However, as Eranti (2017) has shown, politicization based on stakeholder interests - claims making based on "one's own good" - is also a valid option in the Finnish context, in his case in individual complaints about urban planning. For a social movement such as the bicyclists, however, this way of building the common seems to be somewhat detrimental. In sum, it may well be possible to politicize singular issues using the interest-based mode of action and talk, but not to deliberate and build a collective movement. Furthermore, strong familiarity based network has been indicated a good "companion" to justification based public action: it helps sustain the movement and eases internal conflicts without forcing them out the door completely (Luhtakallio \& Tavory 2018).

This analysis has striven to illustrate democracy as a societal pattern and thus stressed the importance of following specific processes of politicization and their conditionings in activist groups; the keys to making sense of what and why seems possible, desirable, and feasible to change in a given context. Understanding the contextual differences in perceived possibilities, desirabilities and feasibilities is crucial in explaining differences in democracies without resorting to methodological nationalism any more than to exaggerated global isomorphism and, ultimately, in figuring out how to succeed global action plans over wicked, pressing problems like global warming.

Much of the problematic of assessing social movement outcomes is embedded in a notion of democracy as a form of governance, rather than a form of society itself (see 
Rosanvallon 2011). In the same pragmatist vein that guides the argument in this paper, Blee $(2012,4)$ points out that in order to assess citizen activism, we should define democracy not as an adjective but a verb, "the action of people as they deliberate and work together to affect society, rather than a form of governance”. This action, I argue, constitutes of processes of politicization that have varying scopes and different scales of successfulness, but nevertheless leave traces both in the environment in which they take place and in the understandings of the people and groups that take part in them.

Literature:

Alapuro, R. 2005. Associations and contention in France and Finland: Constructing the society and describing the society. Scandinavian Political Studies, 28 4, 377-399.

Alapuro, R. 2010. Climate Change and Civil Society (CLIC).

https://tuhat.helsinki.fi/portal/fi/projects/climate-change-and-(1c1f5f4b-d8b6-474a-8dbdd73e10e0b080).html

Baiocchi, G., Bennett, E. A., Cordner, A., Klein, P., \& Savell, S. (2015). Civic imagination: Making a difference in American political life. Routledge.

Benford, R. D., \& Snow, D. A. 2000. Framing processes and social movements: An overview and assessment. Annual review of sociology, 261 , 611-639.

Berglund, E. \& Harper, K. 2001. Citizen sensibilities: Comparing grassroots environmental activism in Finland and Hungary. Antbropology of East Europe Review Vol. 19: 1. 
Berglund, E. 2006. Ecopolitics through ethnography: The cultures of Finland's forestnature. Reimagining political ecology, 97-120.

Blee, K. M. 2012. Democracy in the making: How activist groups form. OUP USA.

Blok, A., \& Meilvang, M. L. \& Carlsen H. 2018. Methods of engagement: On civic participation formats as composition devices in urban planning. European Journal of Cultural and Political Sociology, 5: 1-2, 12-41.

Boltanski, L., \& Thévenot, L. 1991. De la justification. Les économies de la grandeur, Paris, Gallimard.

Carrel, M. 2015. Politicization and publicization: the fragile effects of deliberation in workingclass districts. European Journal of Cultural and Political Sociology, 2: 3-4, 189-210.

McCarthy, J. D., \& Zald, M. N. 1977. Resource mobilization and social movements: A partial theory. American journal of sociology, 82:6, 1212-1241.

ECF 2017. European Cycling Federation https://ecf.com/sites/ecf.com/files/EUCS_full_doc small_file.pdf

Edwards, B., \& Gillham, P. F. 2013. Resource mobilization theory. The Wiley-Blackwell Encyclopedia of Social and Political Movements.

Eliasoph, N., \& Lichterman, P. 2003. Culture in interaction. American Journal of Sociology, 108:4, 735-794

Eranti, V. 2016. Individuals Doing Politics: Urban participation, social media campaigning and online nanopolitics. Publications of the Faculty of Social Sciences. 
Eranti, V. 2017. Re-visiting NIMBY: From conflicting interests to conflicting valuations. The Sociological Review, 65:2 , 285-301.

Eranti, V. 2018. Engagements, grammars, and the public: From the liberal grammar to individual interests. European Journal of Cultural and Political Sociology, 2018: 1-2. In print.

Fine, G. A. 1995. Public narration and group culture: Discerning discourse in social movements. Social movements and culture, 4, 127-43.

FoE 2018. Friends of the Earth Finland http://www.maanystavat.fi/english consulted January $15,2018$.

Fung, A. 2003. Associations and democracy: Between theories, hopes, and realities. Annual review of sociology 29.1, 515-539.

Fung, A., \& Wright, E. O. 2001. Deepening democracy: innovations in empowered participatory governance. Politics \& Society, 29:1, 5-41.

Furness, Z. 2010. One less car: Bicycling and the politics of automobility. Temple University Press.

Gladarev, B., \& Lonkila, M. 2013. Justifying civic activism in Russia and Finland. Journal of Civil Society, 9(4), 375-390.

Hamidi, C. 2006. Éléments pour une approche interactionniste de la politisation. Revue française de science politique, 56:1, 5-25. 
HeCy 2018. The Helsinki Cyclist Association. https://www.hepo.fi/yhdistys/ consulted January 15, 2018.

Helsingin kaupunkisuunnitteluvirasto 2014. Pyöräilyn hyödyt ja kustannukset Helsingissä Helsingin kaupunkisuunnitteluviraston liikennesuunnitteluosaston selvityksiä 2014:5 http://www.hel.fi/hel2/ksv/julkaisut/los 2014-5.pdf

Helsinki City Bike Plan 2014. https://www.hel.fi/hel2/ksv/julkaisut/los_2014-4.pdf

Helsinki 2016 https://dev.hel.fi/paatokset/asia/hel-2015-012598/

Helsinki 2017. https://www.hel.fi/helsinki/fi/kartat-ja-liikenne/pyoraily-ja-kavely/pyorareitit.

Helsinki city bikes 2018. https://www.hsl.fi/en/citybikes

Hämeentie 2016. http://hameentie.fi

Klandermans, B. 1984. Mobilization and participation: Social-psychological expansisons of resource mobilization theory. American sociological review, 583-600.

Klandermans, B. 1992. The social construction of protest and multiorganizational fields. Frontiers in social movement theory, 77-103.

Koopmans, R., \& Statham, P. Eds. 2010. The making of a European public sphere: Media discourse and political contention. Cambridge University Press.

Lichterman, P. 2002. Seeing structure happen: Theory-driven participant observation. Methods of social movement research, 16, 118-145. 
Luhtakallio, E. 2012. Practicing Democracy. Local Activism and Politics in France and Finland. Basingstoke: Palgrave Macmillan.

Luhtakallio, E., Kivekäs, O., Heikinheimo, O., Mauranen, A. \& Nurminen, J. 2012. Critical Bike Ride and 20 Years of Mass Bicycle Demonstrations in Helsinki. In Carlsson, Chris, LisaRuth Elliott \& Adriana Camarena Eds. Shift Happens! Critical Mass at 20. San Francisco: Full Enjoyment Books. 2012.

Luhtakallio, E. \& Tavory, I. 2018. Patterns of engagement: identities and social movement organizations in Finland and Malawi. Theory and Society Vol. 47: 2, 151-174.

Lundbom, P. 2016. Eläinten puolustajat: suomalaisen eläinoikeusaktivismin muuttuva poliittinen tyyli ja toiseus. Jyväskylä studies in education, psychology and social research 570.

Musante, K., \& DeWalt, B. R. 2010. Participant observation: A guide for fieldworkers. Rowman Altamira.

Perälä, R., Hellman, M., \& Leppo, A. 2013. Behind the scenes: the justifications for opioid maintenance treatment in Finland. Substance use \&o misuse, 48(11), 954-965.

Rosanvallon P. 2011 La société des égaux. Collecion «Les livres du nouveau monde ». Paris: Seuil.

Siisiäinen, M. 1992. Social Movements, Voluntary Associations and Cycles of Protest in Finland 1905- 91. Scandinavian Political Studies, 15:1, 21-40.

Snow, D. A., \& Benford, R. D. 1988. Ideology, frame resonance, and participant mobilization. International social movement research, 1:1, 197-217. 
Snow, D., Benford, R., McCammon, H., Hewitt, L., \& Fitzgerald, S. 2014. The Emergence, Development, and Future of the Framing Perspective: 25+ Years Since "Frame Alignment". Mobilization: An International Quarterly, 19:1, $23-46$.

Tavory, I. 2016. Summoned: Identification and religious life in a Jewish neighborhood. University of Chicago Press.

Tavory, I., \& Timmermans, S. 2014. Abductive analysis: Theorizing qualitative research. University of Chicago Press.

Thévenot, L. 2006. L'action au pluriel: sociologie des régimes d'engagement. Éditions La Découverte.

Thévenot, L. 2007. The plurality of cognitive formats and engagements: Moving between the familiar and the public. European Journal of Social Theory 103 : 409-23.

Thévenot, L. 2014. Engaging in the politics of participative art in practice. In: Zembylas, T ed. Artistic Practices. New York: Routledge.

Thévenot, L. 2015. Making commonality in the plural, on the basis of binding engagements. Dumouchel P, Gotoh R Social bonds as freedom: revising the dichotomy of the universal and the particular. Berghahn, New York, 82-108.

Tocqueville, A. D. 1961. orig. 1840. Democracy in America, 2.

Valocchi, S. 2009. The Importance of being "We": Collective Identity and the Mobilizing Work of Progressive Activists in Hartford, Connecticut. Mobilization: An International Quarterly, 141 , 6584. 
Vivanco, L. A. 2013. Reconsidering the bicycle: An anthropological perspective on a new old thing. Routledge.

Warren, Mark E 2001. Democracy and association. Princeton University Press.

Ylä-Anttila, T. \& Luhtakallio, E. 2016. Justifications Analysis: Understanding Moral Evaluations in Public Debates. Sociological Research Online 21:4. 2016.

Ylä-Anttila, T., Vesa, J., Eranti, V., Kukkonen, A., Lehtimäki, T., Lonkila, M., \& Luhtakallio, E. 2018. Up with ecology, down with economy? The consolidation of the idea of climate change mitigation in the global public sphere. European Journal of Communication, 0267323118790155.

Ylä-Anttila, Tuukka. 2017. Familiarity as a tool of populism: Political appropriation of shared experiences and the case of Suvivirsi. Acta Sociologica, 60(4), 342-357.

Zald, M. N., \& Ash, R. 1966. Social movement organizations: Growth, decay and change. Social forces, 443 , 327-341. 